\title{
Changes in stress within grassland ecosystems in the three counties of the source regions of the Yangtze and Yellow Rivers
}

\author{
YiPing FANG ${ }^{1 *}$, DaHe QIN ${ }^{2}$, YongJian DING ${ }^{2}$ \\ ${ }^{1}$ Institute of Mountain Disaster \& Environment, Chinese Academy of Sciences, Chengdu 610041, China; \\ ${ }^{2}$ Cold and Arid Regions Environmental and Engineering Research Institute, Chinese Academy of Sciences, Lanzhou 730000, China
}

\begin{abstract}
Based on a database of more than 40 years of second production process and energy flow records for Maduo, Qumalai and Yushu counties, a dynamic model of the stress within grassland ecosystems was established using a nonlinear regression method for this source regions of the Yangtze and Yellow Rivers. The results show that dynamic curves of stress within grassland ecosystems in the three counties were in the shape of an inverted "U" during the period 1965-2007. It also revealed that the variation in actual amount of livestock inventories reflected the general trends of the stress within the grassland ecosystems in the source regions, although there were many other factors for the increase or reduction in grassland ecosystem stress.
\end{abstract}

Keywords: the source regions of Yangtze and Yellow Rivers; the stress within grassland ecosystems; inverted " $U$ " model; driver

\section{Introduction}

The stress within grassland ecosystems is the synthesis reflection of outside factors (including climate and vegetation changes and human disturbance) on the impact of the grassland ecosystem. In order to track the effects of the stress, much research has focused on grassland plant productivity (i.e. primary productivity) in terms of assessment of productivity of grassland (Huang et al., 2000; Wang et al., 2001; Han et al., 2003; Seaquist et al., 2003; Yao et al., 2004; Zhao et al., 2004; Jiang et al., 2006; Turner et al., 2006; Li et al., 2007; Chen et al., 2008; Prieto-Blanco et al., 2009; Wang et al., 2009), spatial distribution (Piao et al., 2004), influential factors (Li and Huang, 2005; Sun et al., 2005; Hao and Wu, 2006; Han et al., 2007; Zhao, 2007; Guo et al., 2008; Steinshamn and Thuen, 2008; Zhang et al., 2008; Wang and Fang, 2009), sustainable utilization (Shimodaa et al., 2009) as well as effect and adaptation of animal husbandry (An et al., 2001; Kabubo-Mariara, 2009). However, there was little research on the dynamic of grassland ecosystem stress. Understanding the stress change within grassland ecosystems and their drivers is essential to find some measures to enhance positive and minimize negative effects (MEAB, 2003). Recently, Feng et al. (2009) evaluated ecological stress caused by animal husbandry in the source regions of the Yangtze, Yellow and Lancang Rivers over the last 40 years, using an ecological stress-index defined as the ratio between realistic and theoretical carrying capacity of grassland. There is still little research published on the stress process and drivers of grassland ecosystems, especially quantified stress based on the second production process of grassland ecosystems and energy flow in the Qinghai-Tibet Plateau. The objective of this paper is to reveal the long-term change of the stress within grassland ecosystems in the source regions of the Yangtze and Yellow Rivers, using second production process of grassland ecosystem and energy flow.

\section{Study areas and methods}

\subsection{Study areas}

The study areas (source regions of the Yangtze and

Received 2010-01-07, accepted 2010-03-22 doi: 10.3724/SP.J.1227.2010.00116

* Corresponding author: YiPing FANG (E-mail: ypfang@imde.ac.cn; ypfang2004 @yahoo.ca) 
Yellow Rivers) are located at the east of the Qinghai-Tibet Plateau (Fig. 1). It is a typical region of alpine and plateau climate (Li et al., 2006), with mean altitude above $4,000 \mathrm{~m}$, sensitivity to the changes of climate, diversified species of vegetation of high altitude localities (Li et al., 2007), and it is a very important component part of the cryosphere in China. This area contains the headwaters of the Yangtze and Yellow Rivers, with widely distributed wetlands, many lakes and developed river systems, glaciers and permafrost (Yang et al., 2004; Li et al., 2007). The Maduo, Qumalai and Yushu counties with different geographical conditions were chosen as a case study to approach the stress of grassland ecosystems among 12 counties of all the source regions in Qinghai Province (SBQP, 2008) (Table 1).

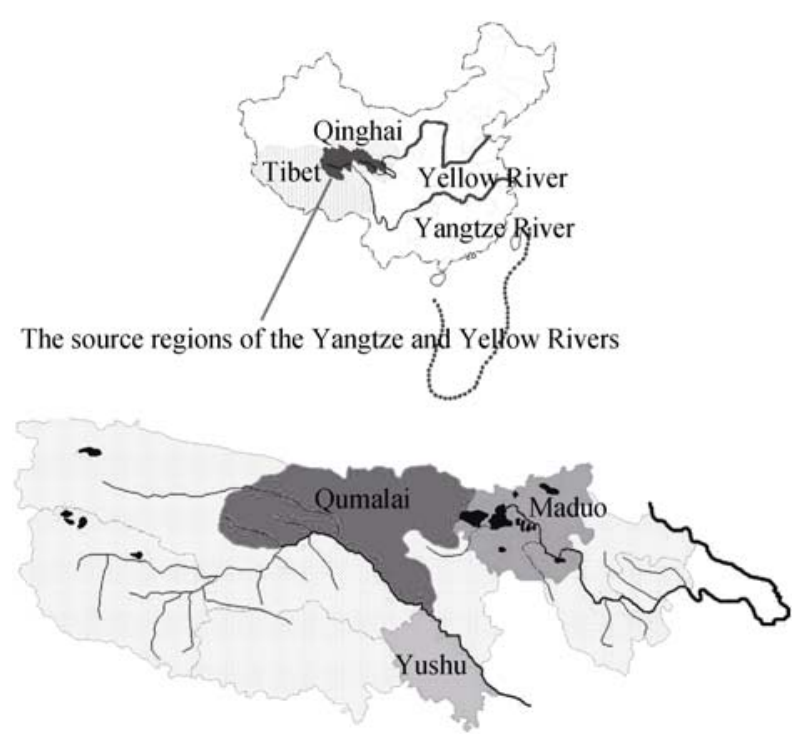

Fig.1 The location of the source regions of the Yangtze, Yellow River and three study areas

Table 1 Information of three counties of the Qinghai province in the east of Qinghai-Tibet Plateau

\begin{tabular}{lllll}
\hline \multirow{2}{*}{ Information } & \multicolumn{3}{c}{ County/prefecture } & $\begin{array}{c}\text { The source regions of the } \\
\text { Yangtze and Yellow Rivers }\end{array}$ \\
\cline { 2 - 4 } Geographic location & Maduo/Guoluo & Qumalai/Yushu & Yushu/Yushu & $32^{\circ} 30^{\prime}-35^{\circ} 40^{\prime} \mathrm{N}$ \\
Mean elevation $(\mathrm{m})$ & $33^{\circ} 50^{\prime}-35^{\circ} 40^{\prime} \mathrm{N}$ & $33^{\circ} 36^{\prime}-35^{\circ} 40^{\prime} \mathrm{N}$ & $93^{\circ} 46^{\prime} \mathrm{N}$ & $90^{\circ} 30^{\prime}-99^{\circ} 45^{\prime} \mathrm{E}$ \\
& $96^{\circ} 55^{\prime}-99^{\circ} 20^{\prime} \mathrm{E}$ & $92^{\circ} 56^{\prime}-97^{\circ} 35^{\prime} \mathrm{E}$ & $4,-97^{\circ} 44^{\prime} \mathrm{E}$ & $3,335-6,564$ \\
Climate feature & $>4,000$ & $3,950-5,590$ & 4,493 & $\begin{array}{l}\text { Typical plateau- } \\
\text { continental climate }\end{array}$ \\
Average temperature $\left({ }^{\circ} \mathrm{C}\right)$ & Semi-humid & Typical plateau- & Typical plateau- \\
Average rainfall $(\mathrm{mm})$ & continental climate & continental climate & continental climate & -0.78 \\
Area $\left(\mathrm{km}{ }^{2}\right)$ & -4.1 & -3.3 & 2.9 & 459.4 \\
Population & 326.3 & $380-470$ & 487 & 200,000 \\
$\begin{array}{l}\text { Proportion of animal husbandry produc- } \\
\text { tion value in regional GDP }(\%)\end{array}$ & 25,240 & 52,500 & 13,462 & 470,000 \\
\hline
\end{tabular}

\subsection{Methodology}

In order to address the complexity of ecosystem stress-factor, the authors focused on the dynamic of grassland ecosystem stress based on the dimension of second production process. The consumption, reduction and livestock inventories are considered together to entirely mirror the energy flow and its direction in the second production process of grassland ecosystem. Therefore, the constructed model of grassland ecosystem stress may consist of the following parts:

$$
P_{e}=\sum_{k=1}^{k=n} H_{k}+\sum_{j=1}^{j=n} R_{j}+\sum_{m=1}^{m=n} P_{m}
$$

where $P_{e}$ is the stress on the grassland ecosystem; $H_{k}$ is the reduced part of droppings, urine and carcasses of animals; $H_{k}=$ (yield of droppings + urine of inventories of cattle + horses + sheep) $\times$ energy transformation constant, based on the structure of present livestock; $R_{j}$ is the energy consumption in respiration of animal for cattle breeding production, and could be measured by using the difference between annual grass consumption of cattle or sheep and increasing amount of cattle body mass (Yang et al., 2008); $P_{m}$ is the second productivity of animal husbandry, representative of yield of livestock products and livestock inventories on hand. The energy values of the elements in the formula are converted into unified units to make it easy to compare (Yang et al., 2008).

In grassland ecosystem, $H_{k}$ is the incoming while $R_{j}$ and $P_{m}$ are outgoing elements, among which $R_{j}$ is 
transmitted in the form of heat energy to the surroundings and most of $P_{m}$ flows out of the ecosystem in the form of livestock products (Yang et al., 2008). Therefore, the $P_{m}$ could be divided as:

$$
P_{m}=\sum A_{i}+\sum M_{j}+\sum N_{k}+\sum W_{n},
$$

where, $\sum A_{i}$ is the amount of livestock inventories at the end of year (J); $\sum M_{j}$ is the total yield of meat $(\mathrm{J})$; $\sum N_{k}$ is the total yield of milk (J), and $\sum W_{n}$ is the total yield of wool (J).

\subsection{Data collection}

In this study, data on livestock inventories, livestock structure and product yield were collected from statistical yearbooks of Qinghai Province, Guoluo and Yushu Tibetan Autonomous Prefectures and relevant counties from 1965 to 2007.

\section{Results}

The result shows that the stress within the grassland ecosystems of Maduo, Qumalai and Yushu counties varies yearly as one-variable Cubic function (Figs. $2-4$ ), and the confidence level for statistical test is above $95 \%$ on average. The correlation coefficients of regression functions are $0.628,0.715$ and 0.916 respectively for Maduo, Qumalai and Yushu.

The stress within grassland ecosystems in the three counties increased rapidly in the 1960s, and reached the peak in the late 1970s and early 1980s, and began to decrease since then. The curves indicate some increases in stress in Maduo and Qumalai after 2003, but not in Yushu country where stress appears to have continued to decrease.

Spatially, it shows the fastest speed of variation of grassland ecosystem stress in the south county Yushu, followed by north countries Qumalai and Maduo (Fig. $5)$. The maximum value of stress of grassland ecosystem in Yushu County is 2.59 and 1.59 times that of Maduo and Qumalai.

The dynamic models of grassland ecosystem stress are displayed as follows respectively based on nonlinear regression analysis:

Maduo County: $y_{1}=9 \mathrm{E}-05 x_{1}^{3}-0.0072 x_{1}^{2}+0.1619 x_{1}+$ $0.0813, R_{1}^{2}=0.6288$,

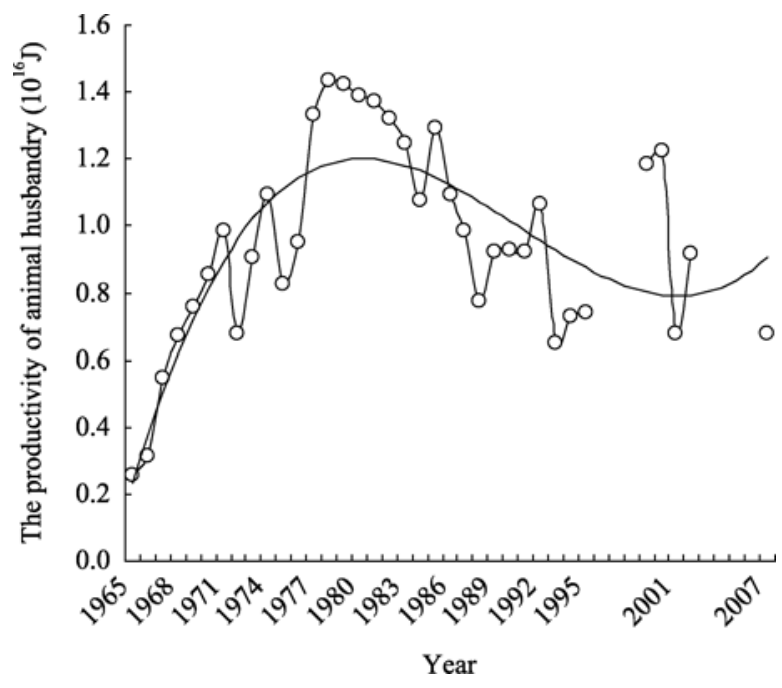

Fig. 2 The stress dynamic of grassland ecosystem in Maduo county

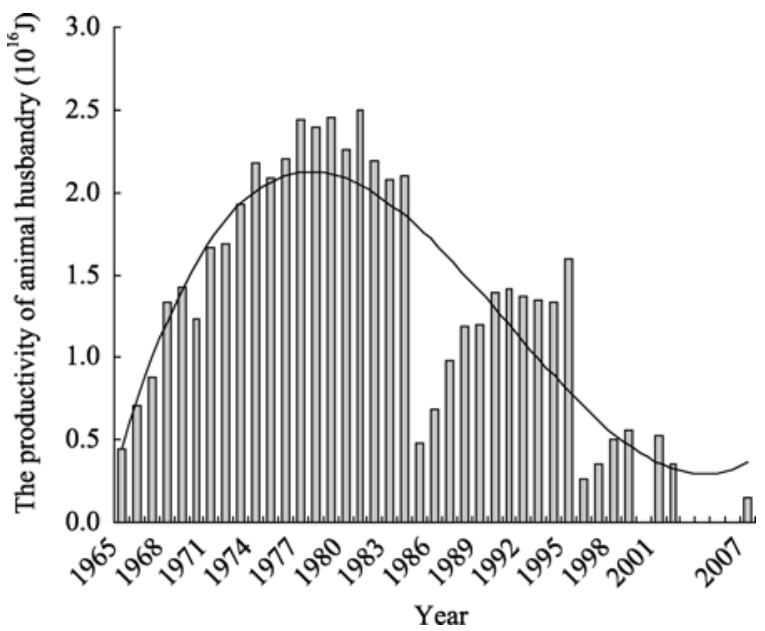

Fig. 3 The stress dynamic of grassland ecosystem in Qumalai county

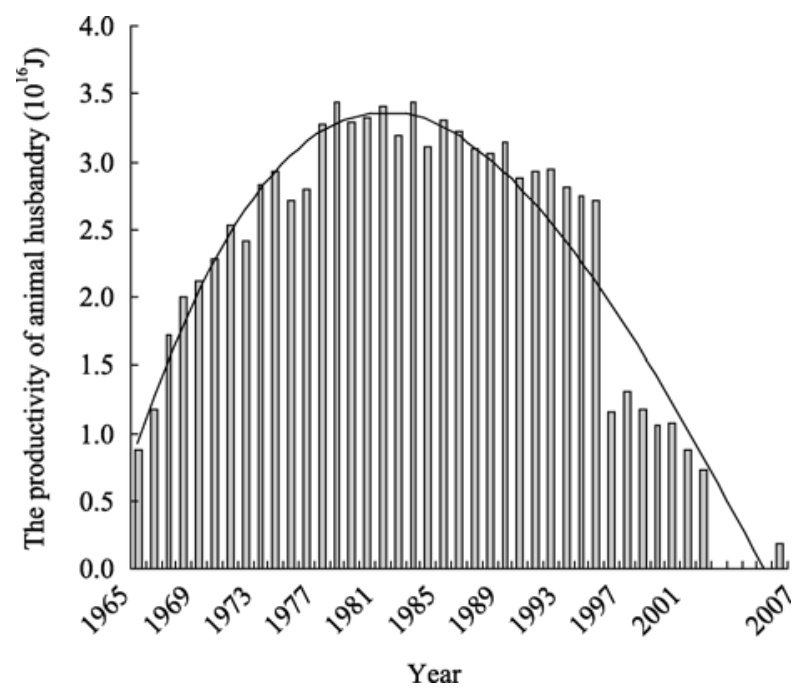

Fig. 4 The stress dynamic of grassland ecosystem in Yushu county 


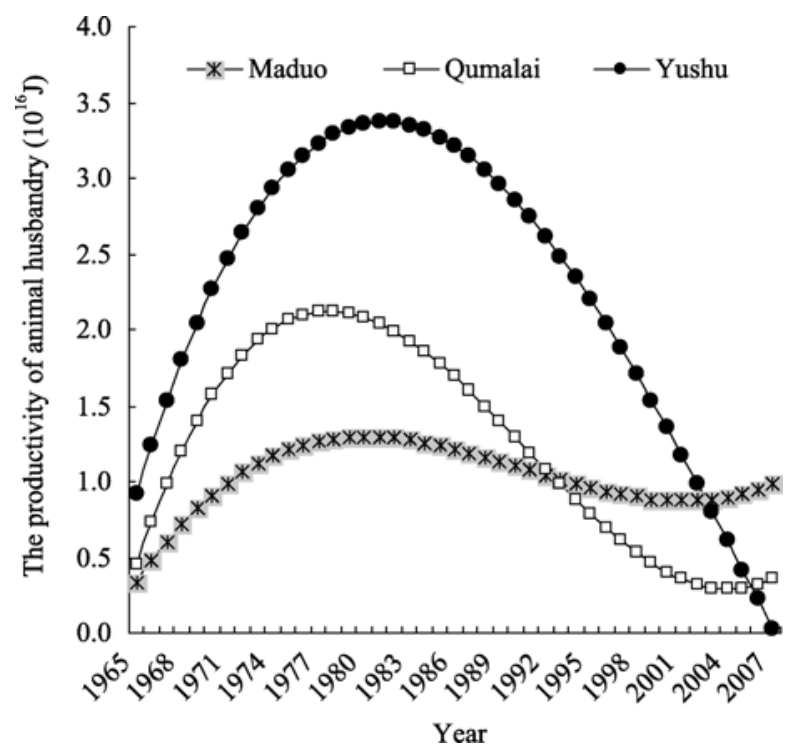

Fig. 5 The dynimic curve of stress of grassland ecosystem in the three cases counties

Qumalai County: $y_{2}=0.0002 x_{2}{ }^{3}-0.0161 x_{2}{ }^{2}+0.3278 x_{2}$ $+0.1379, R_{2}{ }^{2}=0.7157$

Yushu County: $y_{3}=1 \mathrm{E}-04 x_{3}{ }^{3}-0.0128 x_{3}{ }^{2}+0.3526 x_{3}+$ $0.5857, R_{3}{ }^{2}=0.9168$,

where, $y_{i}$ is the grassland ecosystem stress $(1 \mathrm{E}+16 \mathrm{~J})$; $x_{j}$ is the year series $(1965=1), R_{m}{ }^{2}$ is the percentage of variability of the dependent variables explained by the regression equation, indicating the effect of fitting function.

The fitting curves of these three counties (Figs. 2-4) are all in the shape of inverted "U", which means that the stress within the grassland ecosystems increases swiftly at first, then peaked, and subsequently decreased. As the functions (3)-(5) are derivable, and the point exists where the derivative is zero, satisfying the condition that the derivatives at both sides of the point are opposite (left: positive; right: negative), then a maximum value exists. The derivation provides the maximum values from derivation of grassland ecosystem stress were 1.30, 2.12 and $3.37\left(10^{16} \mathrm{~J}\right)$ in Maduo, Qumalai and Yushu respectively in the year of 1980, 1978 and 1981.

\section{Discussion}

The stress within grassland ecosystems is first highly related to the grazing animal. According to the almanac statistics, the number increased abruptly since 1960 and reached the peak in the late 1970s and early 1980s, and then it went down greatly. The change in livestock inventories display the shape of inverted "U's", the same as the change of stress within grassland ecosystems. On the other hand, the rate of domestic animals for sale and commodity in Maduo, Qumalai and Yushu in 2007 was 1.83, 1.18, and 3.07 times of that in 1985, respectively. It takes on the trend of increasing yield of livestock product and declining number of livestock inventories since 1985. In fact, the rate of reduction in livestock inventories is more rapid than the increase rate of livestock production yield, thus the trend in the stress within grassland ecosystems was down.

The inventories of breeding animals was closely related to the fast increase in population from the early 1950 s to the end of the 20 century and people's awareness of market economic reform since 1980 . For example, the population in the source regions was 3.09 times in 2000 of that in 1953 (Wang et al., 2004; Sheng et al., 2007). The population increase led to the increase of livestock inventories from the 1960s to the end of the 1970s and the early 1980s in the collective economy, and the increase of their maximum benefit (Zhang et al., 2007) from commodities of animal products since the 1980 s. The improvement in management techniques and awareness of herders who were educated and trained by local governments has led to a reduction of stress within grassland ecosystems to a certain extent since the $1980 \mathrm{~s}$.

The role of climatic change on ecosystem stress is mainly due to the increase in annual average temperature since the 1960s (Hu et al., 2007) and the decrease of annual rainfall since 1980, especially a sharp decrease in summer and autumn (Hu et al., 2007). This led to climate change (Hu et al., 2007) restricting the growth of seasonal grassland biomass, and thus affecting the growth of livestock and actual stock-carrying capacity. These factors have had an increasing impact on the grassland ecosystem since 1980.

Some remarkable degradation of grassland spatially and temporally also increased the stress within grassland ecosystems since the mid 1970s (Liu et al., 2008), especially from 1986 to 2000 . For example, it has revealed some decreases in the alpine areas of $15.82 \%$, $5.15 \%$ and $24.36 \%$ in high coverage, alpine meadow and swamp meadow, and a $7.5 \%$ decline in the area of 
lake surfaces respectively (Wang et al., 2004). The trend of degradation was still significant from 2000 to 2007, despite the overall slowing of grassland degradation. For example, rodents have damaged one third of grasslands through eating and digging in the past two decades (Fig. 6). Spatially, it shows variation in different regions and vegetation belts (Liu et al., 2008). Much severer degradation occurred in the source region of the Yellow River than the Yangtze River, and a far higher rate of degradation in winter and spring than in summer (Zhang et al., 2006; Liu et al., 2008). Such degradation has exacerbated erosion in the world's highest and largest wetland area, and has decreased carrying capacity of livestock, thus causing further increasing stress on grassland ecosystems.

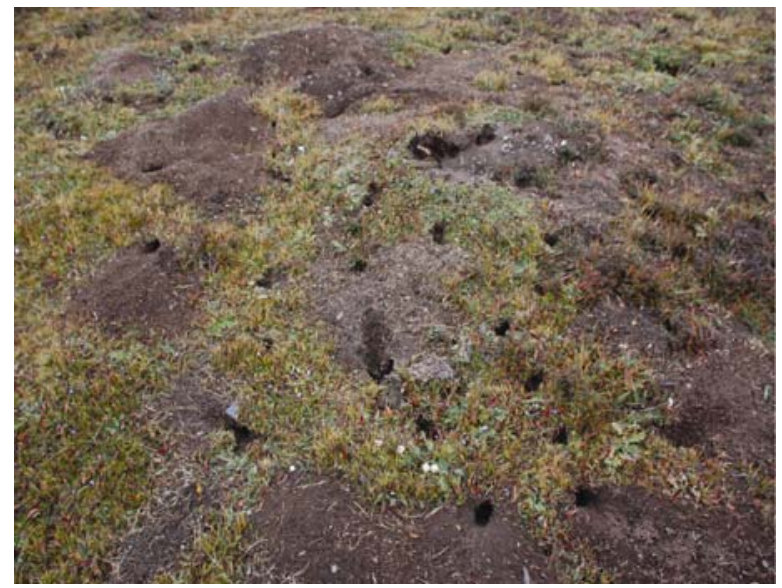

Fig. 6 Rats are causing serious damage on the grassland in the regions

Since the household-based contract responsibility system was implemented in 1984, extensive farming has gradually converted into intensive farming and commodity production. This has brought about adjustments in the structure of livestock products, increasing the rate of commodity and market supply, and grassland protection, rational utilization of grassland, and the national project of returning grazing land to grassland since 2003. Some measures such as the rodent control project, grassland fencing and improved, sown grasslands have laid a good foundation for decreasing grassland stress and a sustainable livestock industry. The constitution and implementation of a series of policies and rules effectively restrained the situation of overgrazing in the source regions and has gradually reversed the trend of increasing stress within grassland ecosystems (Fig. 5).

There are many drivers influencing increased or reduced stress within grassland ecosystems. However, livestock inventories correlate closely with the level of stress within grassland ecosystems. The correlation coefficient is up to 0.85 , that is, the former varies almost directly with the latter. Therefore, the variation in actual amount of livestock inventories in the source regions reflects the general trend in stress within grassland ecosystem there.

In addition, there appeared to be a time lag before the influence of human factors became apparent in the source regions. This was related to the implementation of the household-based contract of grazing land management, the project to return grazing land to grassland, the project to reduce livestock numbers, and an increasing rate of domestic animals and commodities for sale. Due to the above factors' combined influence, the stress within grassland ecosystems in this region has been notably decreasing since the 1980s.

\section{Conclusion}

The annual change curves of stress within grassland ecosystems in Maduo, Qumalai and Yushu counties are all in the shape of inverted "U's", with maximum values respectively occurring in 1980, 1978 and 1981.

The livestock inventories are significantly correlated to the variation of stress within the grassland ecosystem (the correlation coefficient is up to 0.85 ) although there are many factors influencing increases or reductions in grassland ecosystem stress. Therefore, the variation in actual livestock inventories reflects the general trend of the stress within grassland ecosystems in the source regions.

Therefore, it is very necessary approach to improve livestock productivity while reducing overall livestock numbers in order to maintain the production and output of individual flocks and herds to enhance the well-being level while reducing grassland ecosystem stress.

\section{Acknowledgements}

This research was jointed supported by a grant from the National Basic Research Program of China (2007CB411507) and Open Fund of the State Key Laboratory of Cryosphere Science (SKLCS08-05). 


\section{References}

An Y, Li B, Yang C, et al. Stipa grandis grassland productivity and utilization in Inner Mongolia: I. dynamics of standing crop of pastures in grazing system. Acta Prataculturae Sinica, 2001, 10(2): $22-27$.

Chen S R, Wang S X, Zhou Y. Estimation of Chinese grassland productivity using remote sensing. Transactions of the CSAE, 2008, 24(1): 208-212.

Feng Y Z, Yang G H, Wang D X, et al. Ecological stress in grassland ecosystems in source regions of Yangtze, Yellow and Lancang Rivers over last 40 years. Acta Ecologia Sinica, 2009, 29(1): 492-498.

Guo L Y, Wu R, Wang Q C, et al. Influence of climate change on grassland productivity in Xinghai County in the source regions of Yangtze River. Chinese Journal of Grassland, 2008, 32(2): 5-10.

Han D, O'Kiely P, Sun D W. Application of water stress models to estimate the herbage dry matter yield of a permanent grassland pasture sward re-growth. Biosystems Engineering, 2003, 84(1): 101-111.

Han G G, Jiao S Y, Biligetu A. Effects of plant species diversity and productivity under different stocking rates in the Stipa breviflora Griseb, desert steppe. Acta Ecologia Sinica, 2007, 27(1): 182-188.

Hao L, Wu X D. Analysis on the spatiotemporal change of steppe productivity and its driving factors in Inner Mongolia. Arid Zone Research, 2006, 23(4): 577-582.

Hu L W, Yang G H, Feng Y Z, et al. Tendency research of climate warm-dry in source regions of the Yangtze River, the Yellow River and the Lantsang River. Journal of Northwest Sci-Tech University of Agriculture and Forest, 2007, 35(7): 141-146, 153.

Huang J F, Wang X Z, Cai C X, et al. Natural grassland production monitoring using NOAA/AVHRR data in the northern Xinjiang Uygur Autonomous Region. Transactions of the CSAE, 2000, 16(2): $123-127$.

Jiang L P, Qin Z H, Xie W, et al. A research of net primary productivity model of grassland based on MODIS data. Grassland of China, 2006, 28(6): 74-78.

Kabubo-Mariara J. Global warming and livestock husbandry in Kenya: impacts and adaptations. Ecological Economics, 2009, 68(7): 1915-1924.

Li G, Huang G B. The climate change and grassland productivity response to it in the northern farming-pastoral area-taking Dingxi county as an example. Grassland of China, 2005, 27(1): 8-12.

Li G, Xin X P, Wang D L, et al. Application of improved CASA model in productivity evaluation of grassland in Inner Mongolia. Chinese Journal of Ecology, 2007, 26(12): 2100-2106.
Li Y B. Environment evolvement and spatio-temporal patterns in the source regions of Yangtze, Yellow and Langcang Rivers. PhD dissertation, Northwest A \& F University, Shaanxi. 2006.

Li Y B, Yang G H, Wang D X. Environmental status of the source regions of Yangtze, Yellow and Lancang Rivers. Journal of Northwest Sci-Tech University of Agriculture and Forest, 2006, 34(9): 109-114.

Li Y B, Yi H, Yang G H, et al. Biodiversity in the source regions of the Yangtze River, Yellow River and Lancang River. Chinese Journal of Eco-Agriculture, 2007, 15(2): 193-196.

Liu J Y, Xu X L, Shao Q Q. The spatial and temporal characteristics of grassland degradation in the three-river headwaters region in Qinghai Province. Acta Ecologia Sinica, 2008, 63(4): 364-376.

Millennium Ecosystem Assessment Board (MEAB). Ecosystems and Human Well-being: A Framework for Assessment. Washington: Island Press, 2003. 85-106.

Piao S L, Fang J Y, He J S, et al. Spatial distribution of grassland biomass China. Acta Phytoecologica Sinica, 2004, 28(4): 491-498.

Prieto-Blanco A, North P R J, Barnsley M J, et al. Satellite-driven modelling of Net Primary Productivity (NPP): theoretical analysis. Remote Sensing of Environment, 2009, 113(1): 137-147.

Seaquist J W, Olsson L, Ardö J. A remote sensing based primary production model for grassland biomass. Ecological Modeling, 2003, 169(1): 131-155.

Sheng H Y, Yang G H, Wang D X, et al. Current status of grassland resources utilization and the corresponding solutions in a sustainable development context in the regions of three river source. Journal of Northwest Sci-Tech University of Agriculture and Forest, 2007, 35(7): 147-153.

Shimodaa S, Leeb G, Yokoyamac T, et al. Response of ecosystem $\mathrm{CO}_{2}$ exchange to biomass productivity in a high yield grassland. Environmental and Experimental Botany, 2009, 65(2-3): 425-431.

Statistical Bureau of Qinghai Province (SBQP). Year Book of Qinghai Province (2008). Beijing: Chinese Statistical Press, 2008.

Steinshamn H, Thuen E. White or red clover-grass silage in organic dairy milk production: grassland productivity and milk production responses with different levels of concentrate. Livestock Science, 2008, 119(1): 202-215.

Song P F, Hao Z Q. Some ideas about ecological assets assessment. Chinese Journal of Applied Ecology, 2007, 18(10): 2367-2373.

Sun J G, Li B G, Lu Q. Modeling grassland productivity based on DEM in Gonghe basin of Qinghai Province. Resource Science, 2005, 27(4): 44-49. 
Turner P D, Ritts W D, Cohen W B, et al. Evaluation of MODIS NPP and GPP products across multiple biomass. Remote Sensing of Environment, 2006, 102(3-4): 282-292.

Wang D X, Ren G X, Yang G H, et al. The analysis of influencing factors to eco-environmental quality in source regions of Yangtse River and Yellow River and Lantsang River. Journal of Northwest Sci-Tech University of Agriculture and Forest, 2004, 32 (3): 528.

Wang G X, Ding Y J, Wang J, et al. Land ecological changes and evolutional patterns in the source regions of the Yangtze and Yellow Rivers in recent 15 years. Acta Geographica Sinica, 2004, 59(2): 163-173.

Wang J B, Liu J Y, Shao Q Q, et al. Spatial-tempopal patterns of net primary productivity for 1988-2004 based on GlOPEM-CEVSA model in the 'three-river headwaters' region of Qinghai Province, China. Chinese Journal of Plant Ecology, 2009, 33(2): 254-269.

Wang W, Fang J Y. Soil respiration and human effects on global grasslands. Global and Planetary Change, 2009, 67(1-2): 20-28.

Wang X Z, Du G Z, Liang T G, et al. The establishment of grassland productive assessment model and the determination of precipitation resource distribution pattern of Gannan Tibetan Autonomous Prefecture based on RS and GIS. Acta Prataculturae Sinica, 2001, 10(2): 95-102.

Yang G H, Wang D X, Feng Y Z, et al. Eco-environmental Change and Assessment of Quality in the Source Regions of Yangzte River,
Yellow River and Lancang River. Beijing: China Science Press, 2008

Yang J P, Ding Y J, Chen R S, et al. Permafrost change and its effect on eco-environment in the source regions of the Yangtze and Yellow Rivers. Journal of Mountain Science, 2004, 22 (3): 278-285.

Yao Y B, Zhang X Y, Zhu G Q, et al. Assessment of climatic productivity of herbage for natural grasslands in the northeastern Qinghai-Tibet Plateau. Chinese Journal of Agrometeorology, 2004, 25(1): $32-34$.

Zhang S, Liu X B, Wang X. The economic model of grassland ecosystem sustainable development, Inquiry into Economic Issues, 2007, 8: 87-92.

Zhang T H, Zhao H L, Li Y L, et al. Effect of irrigation and fertilizer on grassland productivity in Horqin Sandy Land. Acta Prataculturae Sinica, 2007, 17(1): 36-42.

Zhang Y L, Liu L S, Bai W Q, et al. Grassland degradation in the source region of the Yellow River. Acta Geographica Sinica, 2006, 61(1): $3-14$.

Zhao B R, Liu C, Liu A J, et al. Estimate the yield of grassland using MODIS/NDVI - a case study of the grassland in Xilinguole in Inner Mongolia. Pratacultural Science, 2004, 21(8): 12-15.

Zhao H Y. Impacts of climate change on forage potential climate productivity in typical grassland. Chinese Journal of Agrometeorology, 2007, 28(3): 281-284. 